that the contributions from the integrations along $\mathrm{A}^{\prime} \mathrm{D}^{\prime}$ and $\mathrm{AD}$ vanish as $R$ goes to infinity. In this manner, one can pass from the representation (12) for the temperature in the cylinder to Eq. (13), which is more suitable for numerical work.

If $\varphi(p)$ involves the delta function, or $\varphi_{+}(w)$ or $\varphi_{-}(w)$ contains terms which are not regular in the domains (15) and (16), the contributions due to these terms have to be evaluated separately.

\section{Acknowledgement}

The authors are greatly indebted to Professor E. Sternberg who read the mansucript.

\section{References}

(1) H.S. Carslow and J.C. Jaeger: Conduction of heat in solids, (1948), p. 223, Oxford.

(2) D. Rosenthal: Trans. ASME, Vol.68 (1946), p. 849.

(3) T. Nakada and M. Hashimoto: Trans. Japan Soc. Mech. Engrs., Vol. 28, No. 189 (1962) p. 577.

(4) D. Rosnethal and R.H. Cameron:- Trans. ASME, Vol. 69 (1947), p. 961.

(5) E. Kasahara: Proc. Fac. Engng. Keio Univ., Vol. 9, No. $32(1956)$, p. 13.

(6) E. Melan und H. Parkus: Warmespannugen, (1953), Wien. Springer.

(7) H. Parkus: Instationare Warmespannungen, (1959), Wien. Springer.

(8) W. Nowacki: Thermoelasticity, (1962), Pergamon.

(9) C.K. Youngdahl and E. Sternberg: Trans. ASME Ser. E. Vol. 28, No. 1 (1961), p. 25

(10) I.N. Sneddon: Fourier Transforms, (1951), McGraw Hill.

(11) G. N. Watson: Theory of Bessel Functions, (1932), Oxford.

(12) Staff of the Bateman Manuscript Project: Tables of Integral Transforms, Vol. 1 (1954), McGrawHill.

$539.431: 539.388 .1: 669.355^{\prime}-191$

\title{
Fatigue Damage of 7-3 Brass Specimens*
}

\author{
By Tadasi IsrBAsI**
}

The nature of the fatigue damage of 7-3 brass specimens is quite the same as what occurs in 6-4 brass or in low carbon steel specimens. The damage is confined within a thin surface layer of the specimen and cannot be removed by stress relief annealing. The thickness of the damaged layer becomes greater when the applied stress is high and the number of the stress repetitions is large. The fatigue stressing hardens the material but the hardening can be removed by stress relief annealing.

By taking X-ray diffraction patterns of the surface as well as of the portions beneath the surface of the specimens, it was revealed that the distortion and fragmentation of the grain in fatigued specimens decrease as the distance of the irradiated grain from the surface increases and it was concluded that, as the thickness of the severely damage layer reaches some threshold value of one or two grains thickness, fatigue cracks develop there which, in most cases, eventually cause the plain specimens to break down.

\section{Introduction}

By annealing and electro-polishing procedure it was revealed that;

1) The damage done by the alternating stressing is confined within a thin surface layer of the specimens. The thickness of the damaged layer increases when the applied stress is high and the number of stress repetitions is large and cannot be removed by stress relief annealing.

2) The thickness of the damaged layer seems

* Received 3rd June, 1963.

** Professor, Faculty of Engineering, Kyushu University, Fukuoka. to increase grain by grain.

3) The fatigue stressing hardens the material beneath the surface but this hardening can be removed by stress relief annealing.

Above results were obtained using 6-4 brass $^{(1)}$ and low carbon steel $(0.35 \% \mathrm{C})$ specimens ${ }^{(2)}$. Since those materials are not single phased materials it was desirable to make the same kind of experiments with single phased materials. The results of experiments reported here were obtained with 7-3 brass specimens (single phased material) using annealing and electro-polishing procedure as well as taking X-ray diffraction patterns of damaged specimens. 


\section{Material used and method of testing}

The material used was $7-3$ brass $(69.85 \% \mathrm{Cu}$, $\mathrm{Pb}$ trace, $0.01 \% \mathrm{Fe}$, balance $\mathrm{Zn}$; mean grain size

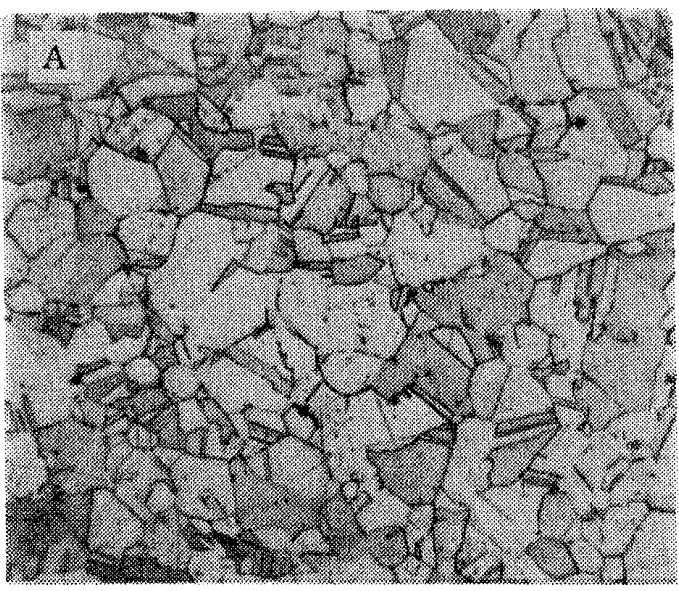

Specimen No. $39(\sigma=0, N=0)$

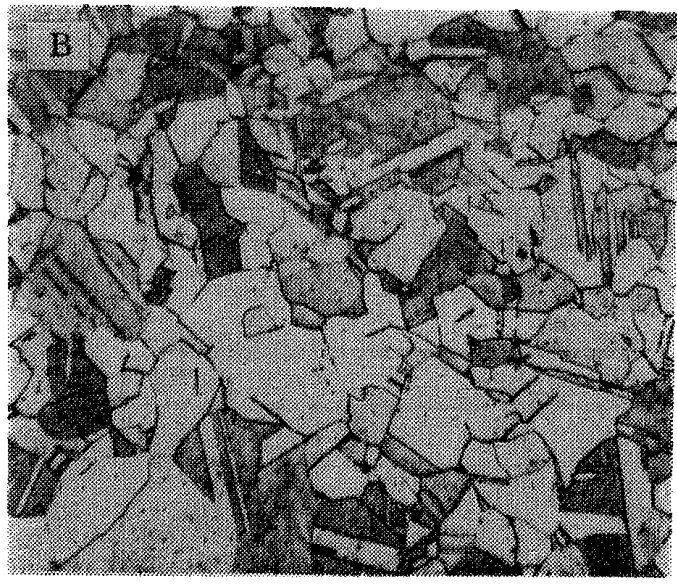

Specimen No. 24, This specimen was stressed to $14.5 \mathrm{~kg} / \mathrm{mm}^{2}$ for $13.451 \times 10^{6}$ repetitions and failed. It was annealed 18 times during these repetitions

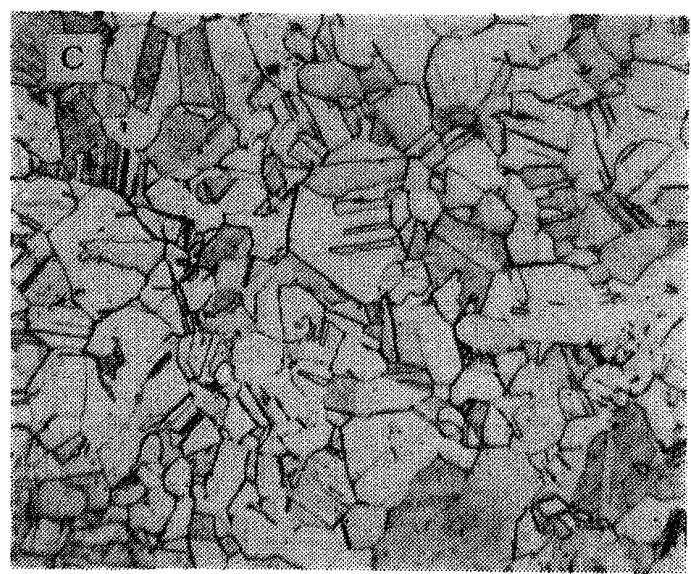

Specimen No. 26, This specimen was broken under the stress of $14.5 \mathrm{~kg} / \mathrm{mm}^{2}$ after 19 repeti tions of annealing. Stress repetition to failure was about $1.74 \times 10^{6}$

Fig. 1 Micrographs of the materials, $\times 200$
$0.03 \sim 0.04 \mathrm{~mm}$ ) which was offered by Dr. K. Takeuchi of the Sumitomo Light Alloy Mfg. Co., Japan, in annealed state $\left(470 \sim 475^{\circ} \mathrm{C}, 2 \mathrm{hr}\right.$.). All specimens were turned out from bars of $17 \mathrm{~mm}$ in diameter.

Fig. 1 (A) shows the micrograph of the original state (annealed state), while Fig. 1 (B) shows the surface of the specimen subjected to rotary bending stress of $14.5 \mathrm{~kg} / \mathrm{mm}^{2}$ repeated $13.451 \times 10^{6}$ times, during which the specimen was annealed 18 times at $400^{\circ} \mathrm{C}$ for $30 \mathrm{~min}$ regularly [c. f. Fig. 4 (a)].

The micrograph of Fig. 1 (C) shows the part near the surface of the specimen which was broken under the stress of $14.5 \mathrm{~kg} / \mathrm{mm}^{2}$ after 19 repetitions of annealing $\left(400^{\circ} \mathrm{C}, 30 \mathrm{~min}\right)$. The stress repetitions to failure was about $1.74 \times 10^{6}$.

The mechanical properties of the materials (mean value of 14 specimens) are: proof stress for $0.2 \%$ set was $13.2 \mathrm{~kg} / \mathrm{mm}^{2}$, tensile strength was $38.5 \mathrm{~kg} / \mathrm{mm}^{2}$, actual stress at fracture was $104.2 \mathrm{~kg} / \mathrm{mm}^{2}$, area contraction was $74 \%$, elongation was $66 \%$ and fatigue limit was $13.0 \mathrm{~kg} / \mathrm{mm}^{2}$.

Endurance curve shown in Fig. 2 was obtained with electro-polished specimens each about $11 \mathrm{~mm}$ in dia. and the rate of stress repetitions was about 2500 per minute. (By taking $\mathrm{X}$-ray diffraction patterns of the specimens it was revealed that when the process of turning the specimens from the original bars was severe, the region of the severely deformed part near the surface of the specimens was somewhat thicker than $30 \mu$, but the specimen used for the determination of the endurance curve in Fig. 2 was electro-polished to take off the surface layer of about $30 \mu$ thick.)

For detailed discussion of the fatigue life of the material itself, it will be necessary to test more specimens than shown in Fig. 2 but, as will be stated below, since localization of the damage is so evident that the conclusions reached would not be misleading because of the scattering of the endurance lives, so we did not make detailed discussions

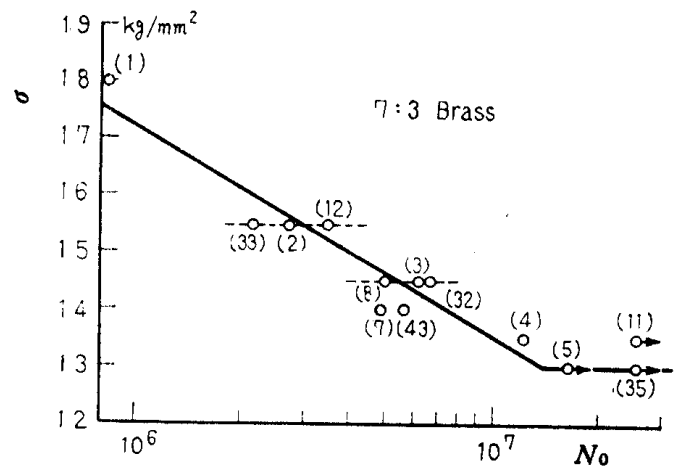

Number in the bracket is the specimen No.

Fig. 2 Endurance curve of the specimens with electro-polished surface 
about the scattering of the endurance lives of the material.

Experimental procedures (in the following this is abbreviated as A.P. procedure) are as follows; After a specimen is subjected to a rotary bending stress $\sigma$ for $N_{1}$ repetitions, the surface of the specimen is polished off mechanically by an amount of $\Delta r_{1}$ with 04 emery paper followed by potannealing for $30 \mathrm{~min}$ at $400^{\circ} \mathrm{C}$ avoiding oxidation of the surface. The specimen is then electro-polished to remove the surface layer to a thickness of $\Delta r_{2}$. When the layer to be removed is thin, mechanical polishing is omitted and only electro-polishing is done. The thickness $\Delta r_{2}$ of the layer removed by electro-polishing was about $30 \pm 3$ microns in all cases of the experiments.

In fatigue tests, for one specimen, $\sigma, \Delta r\left(=\Delta r_{1}\right.$ $\left.+\Delta r_{2}\right)$ and $N_{1}$ were kept constant and the fatigue life of the specimen was measured. The specimen was, therefore, subjected to repeated polishing and annealing after every $N_{1}$ cycles of stress repetitions until it failed under the applied stress $\sigma$. For another specimen, $\sigma$, or $\Delta r$ or $N_{1}$ was changed and its fatigue life was measured, and so forth.

\section{Results of tests and discussions}

In Fig. 3 to Fig. 5 numerals such as (8), (3), for example, represent the specimen number. Life of a specimen is given by the abscissa of the black point at the end of each horizontal line. Black point with an arrow shows that the specimen did not fail. At the number of stress repetitions corresponding to the abscissa of the vertical dotted lines, stress relief annealing $\left(400^{\circ} \mathrm{C}, 30 \mathrm{~min}\right)$ and polishing for removal of the layer were carried out to a thickness of $\Delta r . N_{0}$ is the life of specimen stressed without intermediate A.P. procedure.

a) Case of $\sigma=13.5 \mathrm{~kg} / \mathrm{mm}^{2}$ (Fig.3) Although the specimen (11) did not fail and survived $25.922 \times$ $10^{6}$ repetitions of stress without intermediate $\mathrm{A} . \mathrm{P}$. procedures as shown in Fig. 3 the life of the specimen under the stress $13.5 \mathrm{~kg} / \mathrm{mm}^{2}$ was regarded to be $N_{0}=12.05 \times 10^{6}$ which was nearly equal to the life of the specimen (4) (Fig. 2).

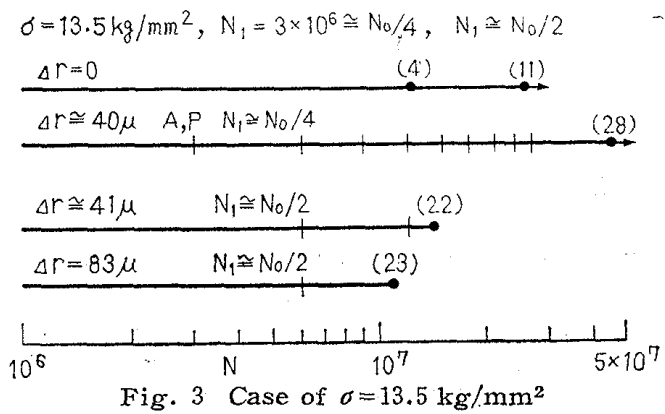

Specimen (28) survived 9 repetitions of A.P. procedures $\left(N_{1}=3 \times 10^{6} \cong 0.25 N_{0}, \Delta r=40 \mu\right)$, and after the last A. P. procedure it endured $18.053 \times 10^{6}$ repetitions of stress, this number of stress repetitions is a little larger than the life of the specimen (4), showing that the thickness of a severely damaged layer during $N_{1}=3 \times 10^{6}$ under the stress of $13.5 \mathrm{~kg} / \mathrm{mm}^{2}$ is less than $40 \mu$. Fig. 3 shows also that the thickness of the damaged surface layer is thicker than $80 \mu$ when the same stress is repeated to about one half the expected normal life $\left(N_{1} \cong\right.$ $0.5 N_{0}$ ) of the specimen.

b) Case of $\sigma=14.5 \mathrm{~kg} / \mathrm{mm}^{2}$ (Fig. 4) The expected normal life of the specimen under the stress of $14.5 \mathrm{~kg} / \mathrm{mm}^{2}$ is about $5.5 \times 10^{6}$ as can be seen from Fig. 2. Now referring to Fig. 4 we see that the total life of the specimen (24), which, after surviving 18 repetitions of A.P. procedures $(\Delta r=40 \mu)$, was broken at $3.241 \times 10^{6}$ stress repetitions, was more than two times the expected normal life of the specimen. It seems, therefore, that the thickness of the severely damaged surface layer during the repetitions $N_{1}=0.1 N_{0}$ is about $40 \mu$.

But since the number of stress repetitions ( $3.241 \times$ $10^{6}$ ) which the specimen (24) endured in 18 times of A.P. procedures is about one half the normal

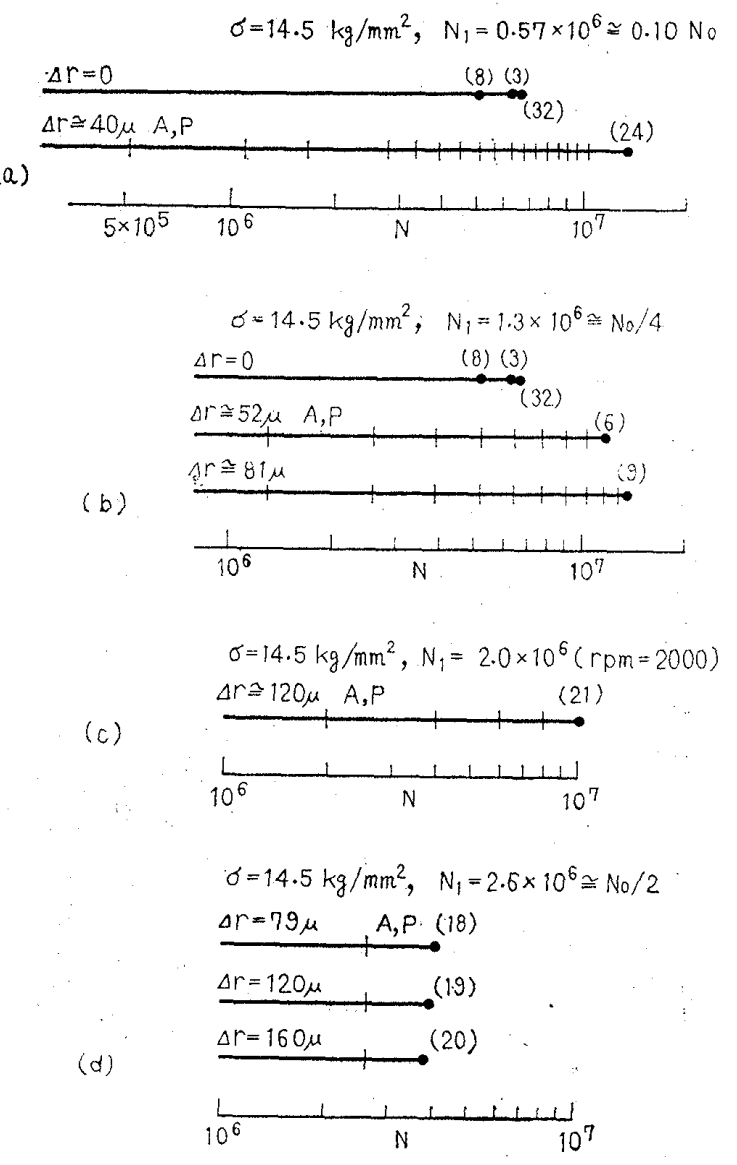

Fig. 4 Case of $\sigma=14.5 \mathrm{~kg} / \mathrm{mm}^{2}$ 
expected life of the specimen under the stress of $14.5 \mathrm{~kg} / \mathrm{mm}^{2}$, it may be concluded that the material suffered in some way from the repetitions of A.P. procedures. That this damage will be due to the effect of annealing in A.P. procedure can be seen from the results of the specimen (15), (26) and (29) as will be explained below.

The fact that the life of a fatigued specimen can be prolonged by removal of its surface layer means that the damage due to fatigue stressing is confined mainly to the surface of the specimen.

Fig. 4 (b) and (c) show that the thickness of the surface layer to be removed to prolong the life becomes greater as the number of stress repetitions increases. Further Fig. 4 (d) shows that the thickness of the damaged surface layer developed in the specimen during stress repetitions of one half of its expected normal life reaches more than $160 \mu$ (this corresponds to the magnitude of 4 grain size).

c) Case of stress $15.5 \mathrm{~kg} / \mathrm{mm}^{2}$ (Fig. 5) The normal expected life of the specimen under the stress of $15.5 \mathrm{~kg} / \mathrm{mm}^{2}$ is about $3 \times 10^{6}$ as can be seen from Fig. 2. Fig. 5 shows the results of tests. The thickness of the damaged layer developed during stress repetitions of one tenth of its normal life is about $40 \mu$. Specimen (15) after surviving 16 repetitions failed after about $1.52 \times 10^{6}$ repetitions of the stress. This number of repetitions is about one half of the expected normal life of the specimen. About this, the same thing as about the test piece (24) may be said.

Fig. 5 shows that the thickness of the severely damaged layer developed during $1 / 4$ of its normal

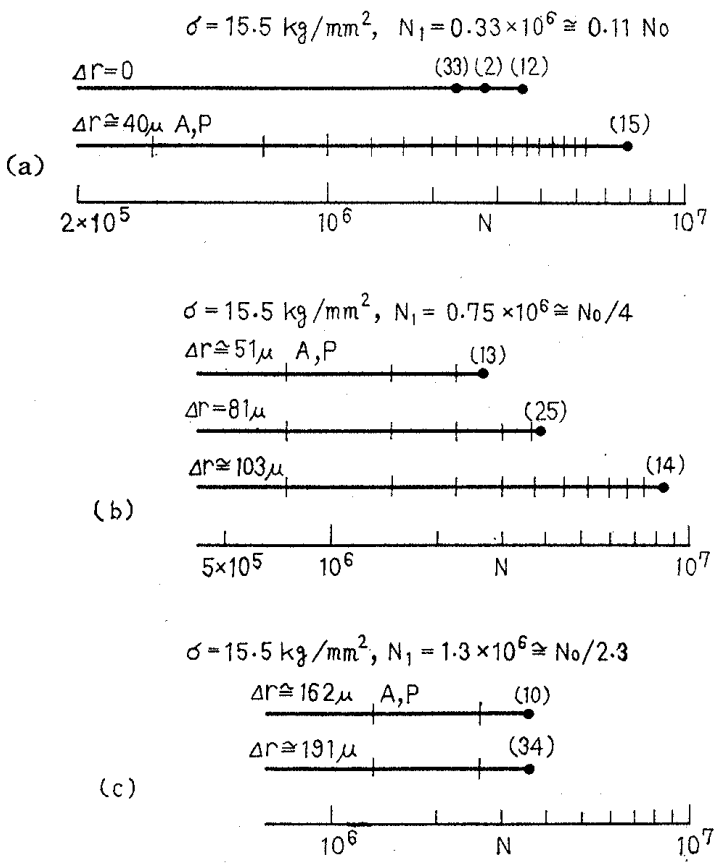

Fig. 5 Case of $\sigma=15.5 \mathrm{~kg} / \mathrm{mm}^{2}$ life is about $100 \mu$. The thickness will increase to about $200 \mu$ when the stress repetition is continued to about $43 \%$ of the normal life of the specimen.

Above results suggest that the main fatigue damage is initially confined within a thin surface layer of the specimen and as the stress repetition continues the thickness of the damage layer increases.

It is also true, as the above experiments show, that even if the damaged layer is removed the life of the specimen can not be prolonged infinitely.

For these facts, the following two factors, viz. the detrimental effect of repeated annealing and the hardening effect of coaxing of the stress, may be responsible.

To see the detrimental effect of the repeated annealing, specimens (26) and (29) were tested. Specimen (26) was annealed $\left(400^{\circ} \mathrm{C}, 30 \mathrm{~min}\right) 19$ times repeatedly in a stainless steel pipe to avoid surface oxidation and then the surface was electropolished to remove the surface layer of about $31 \mu$ thick and then it was tested under the stress of $14.5 \mathrm{~kg} / \mathrm{mm}^{2}$. The life of this specimen was about $1.74 \times 10^{6}$. This life was about one third of the expected normal life of the specimen in as received condition. The specimen (29) was annealed 16 times repeatedly, and then the surface layer of about $31 \mu$ thick was removed by electro-polishing. Then it was tested under the stress of $15.5 \mathrm{~kg} / \mathrm{mm}^{2}$. The life was about $75 \%\left(2.33 \times 10^{6}\right)$ of the expected normal life $\left(N_{0}=3.0 \times 10^{6}\right)$. Although the figure $75 \%$ may lie in the region of scattering of the fatigue lives, above two facts together with the results of the specimens (24) and (15) suggest that repeated annealing $\left(400^{\circ} \mathrm{C}, 30 \mathrm{~min}\right)$ seems to shorten the life of the specimens. No evidence, however, was observed about the grain growth in the annealed specimens (c. f. Fig. 1).

Coaxing effect will strengthen the inner part of the specimen. In our experiments the part at the depth $n \Delta r$ beneath the surface of the specimen comes eventually to the surface of the specimen after $n$-times repetitions of polishing (and annealing), since by each polishing the surface layer of thickness $\Delta r$ is removed. In a specimen of $2 a$ dia. under bending stressing, this part will undergo the stress levels $\sigma(1-n \Delta r / a), \sigma\{1-(n-1) \Delta r / a\}, \cdots \cdots$ $\sigma(1-\Delta r / a)$ until it comes to the surface in such way that at each stress level the stress is repeated $N_{1}$ times and so due to this coaxing effect the fatigue strength of that part may change. It will be natural to conclude that if the stress relief annealing $\left(400^{\circ} \mathrm{C}, 30 \mathrm{~min}\right)$ nullifies the strain hardening due to repeated stressing, the strengthening due to coaxing will also be removed or become 
very small after annealing.

To confirm this we examined the distribution of the hardness over the cross section of a fatigued specimen before and after annealing. The results are shown in Figs. 6 and 7. Fig. 6 shows the microhardness over the section (several millimeters apart from the fractured section) of the specimen (9) which was tested under the stress of $14.5 \mathrm{~kg} /$ $\mathrm{mm}^{2}$. This specimen as shown in Fig. 4 (b) endured 10 repetitions of A.P. procedures, so Fig. 6 can be seen to give the hardness of the specimen after stress repetitions. Mean-while, Fig. 7 shows the distribution of hardness over a section of the same specimen after annealing $\left(400^{\circ} \mathrm{C}, 30 \mathrm{~min}\right)$. These Figures show that the strain hardening due to stress repetitions disappears after such annealing. We concluded, therefore, that the coaxing effect will also disappear by such stress relief annealing.

Fig. 8 shows the relations between the thickness $\Delta r_{0}$ of the damaged layer, as determined by the method stated above, and the magnitude of applied stress or number of stress repetitions. The upward arrow in the Figs. shows that the thickness of the damage layer is larger than that shown by the point and the point with downward arrow shows that the damaged layer is thinner than that shown by the point.

\section{X-ray investigation}

As the surface damage due to fatigue seems mainly due to the appearance of extrusions and

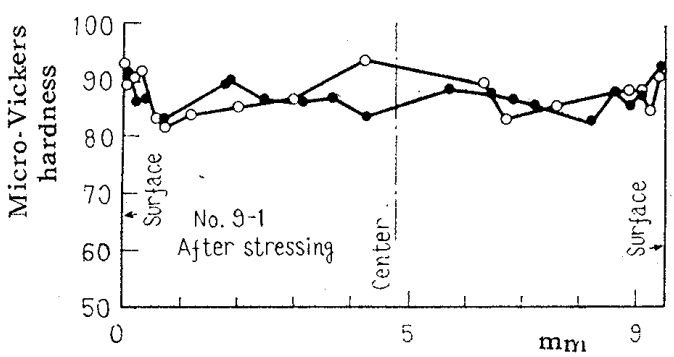

Fig. 6 Micro-hardness distribution over the cross section of specimen No. 9 [c.f Fig.4(b)]. This section is electro polished before measurement

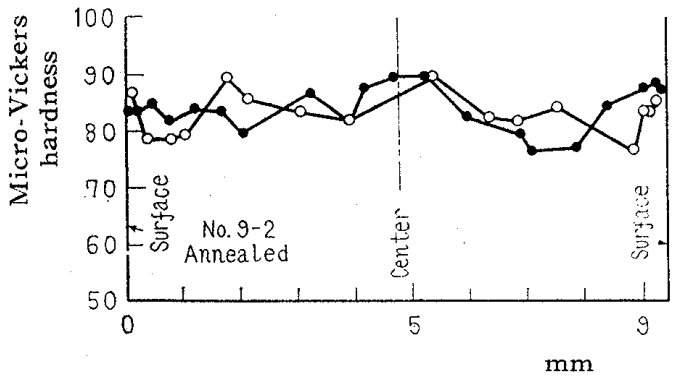

Fig. 7 Micro-hardness distribution over the cross section of specimen No. 9 in an nealed state. This section is electropolished before measurement intrusions, the grain on the surface of the specimen will suffer the damage first. In order that the damage may proceed inward, extrusions and intrusions of the material must appear at the grain boundary such as $A^{\prime} B^{\prime}$ [Fig. 9(a)] after the surface grain $\mathrm{ABB}^{\prime} \mathrm{A}^{\prime}$ has been damaged by stressing. But since the boundary $A^{\prime} B^{\prime}$ is not a free surface as $A B$ is, the occurrence of extrusions and intrusions will be more difficult than on the surface $A B$. Occurrence of extrusions and intrusions will be more difficult on the grain boundary $\mathrm{A}^{\prime \prime} \mathrm{B}^{\prime \prime}$, and so forth. In spite of this the damage proceeds into the interior of the specimen as our experiment shows, therefore some kind of damage, e. g. microcrack formation must take place at a time when the thickness of the damaged part reaches some extent.

It is not ascertained that microcrack formation can be detected by $\mathrm{X}$-ray investigation but some evidences about the inward penetration of fatigue damage will be obtained if the X-ray diffraction patterns from various parts beneath the damaged surface of fatigued specimens are examined, since the sharpness of the diffraction spots will reveal something about the crystalline state of the fatigued

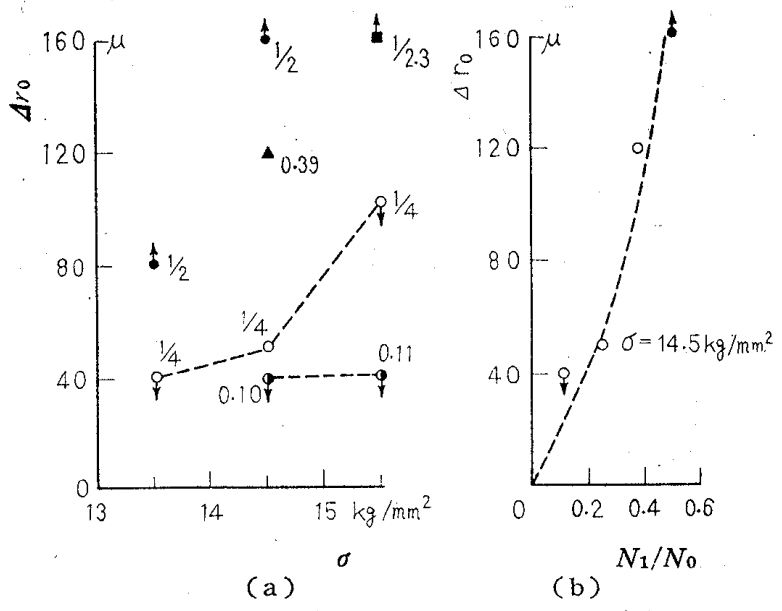

Numbers in (a) are the ratio of $N_{1} / N_{0}$

Fig. 8 Relations between the thickness $\Delta$ ro of damaged layer and applied stress or its number of repetitions

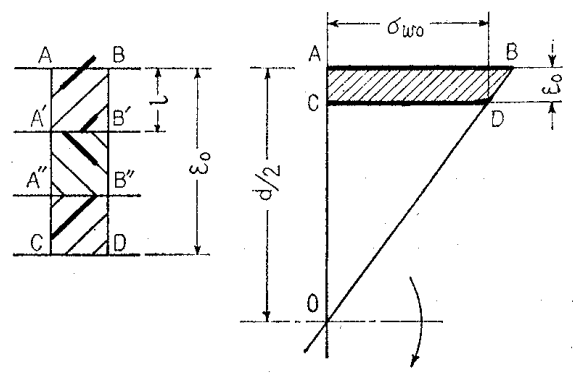

(a)

(b)

Fig. 9 Schematical diagram. (a) The thick lines represent slip lines. (b) $d$ is the dia. of specimen 
specimen.

In the first place we examined whether the thickness of the damaged layer determined by A.P. procedure will or will not be the same as that determined by $\mathrm{X}$-ray method. Fig. 10 shows the diffraction patterns (Co radiation with $\mathrm{Fe}$ filter, dia. of the beam was $0.86 \mathrm{~mm}$ ) of various parts beneath the surface of the specimen subjected to the stress of $15.5 \mathrm{~kg} / \mathrm{mm}^{2}$ for $\sim N_{0} / 4=0.75 \times 10^{6}$. In this Fig., $(17-2)$ is the pattern from the surface and (17-4) is one from about 1 grain $(49 \mu)$ below and (17-5) is about 2 to 3 grains $(100 \mu)$ below and $(17-10)$ is about 4 to 5 grains $(184 \mu)$ below the surface of the specimen respectively. The spots in the Figure become sharper as the diffracting part deepens into the interior of the specimen.

This is an evidence of the fact that large plastic strain is confined within 2 or 3 grains beneath the surface. This thickness coincides with the thickness of damaged layer obtained by A.P. procedure approximately, which was about $100 \mu$ in this case [c.f. Fig. 5 (b)].

$(17-2)$, Surface

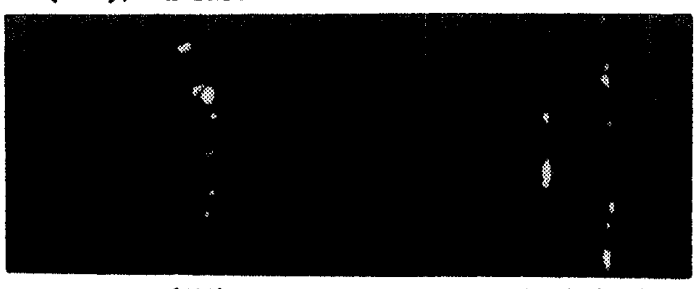

(400)

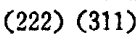

$(17-4), 49 \mu$

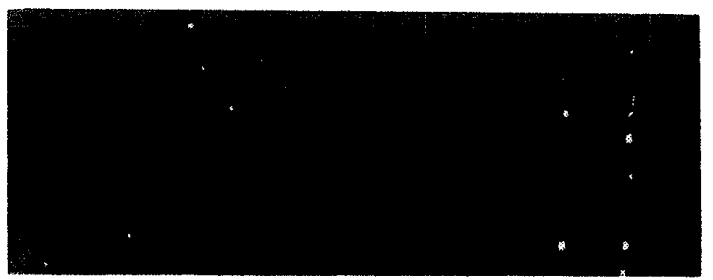

$(17-5), 100 \mu$

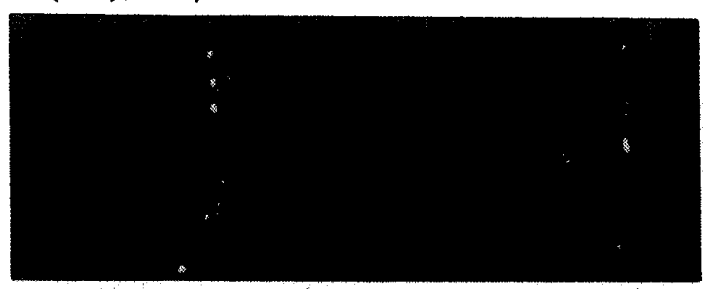

$(17-10), 184 \mu$

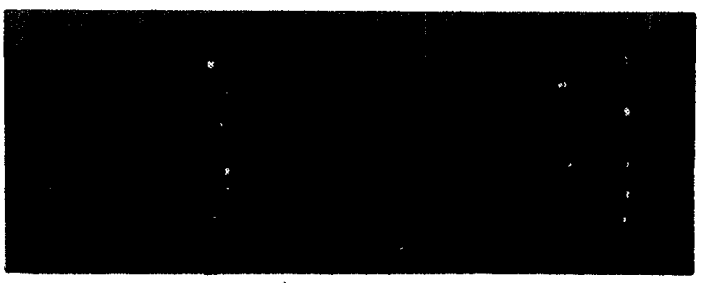

$a=15,5 \mathrm{~kg} / \mathrm{mm}^{2}, N_{1}=0.75 \times 10^{6}$

Fig. 10 Diffraction patterns of specimen No. 17
Fig. 11 shows the patterns of the specimen subjected to repeated stress of $15.5 \mathrm{~kg} / \mathrm{mm}^{2}$ for about $43 \%$ of the expected normal life of the specimen. In this Fig., (16-2) is the pattern from the surface and (16-3) is one from $49 \mu$ below and $(16-5)$ is one about $100 \mu$ below the surface of the specimen; (16-7) and (16-9) are the patterns from the layers about $140 \mu$ and $180 \mu$ below the surface respectively. From this Fig. we see that the expanded spots of the pattern (16-2) are also expanded in (16-9) showing that even $180 \mu$ below the surface there remains some disturbance in crystal planes. This fact coincided approximately with the result obtained by $A . P$. procedure [c.f. Fig. 5 (c)]. Above results lead us to conclude that (16-2), Surface

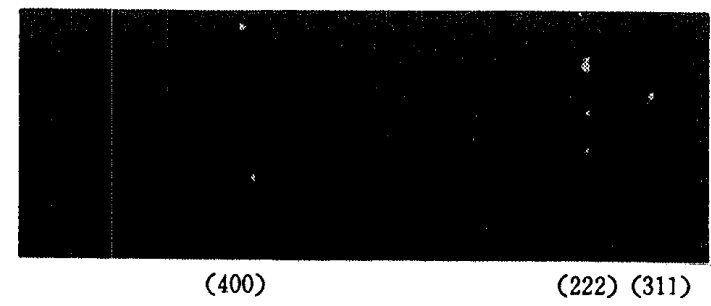

$(16-3), 49 \mu$

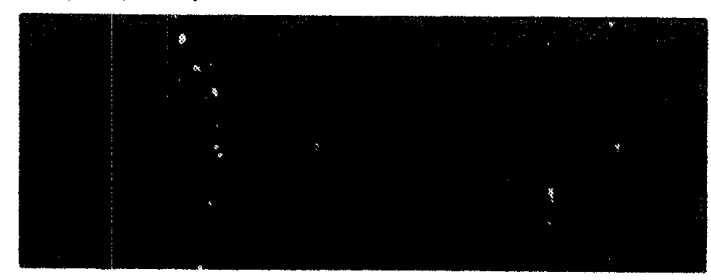

(16-5), $100 \mu$

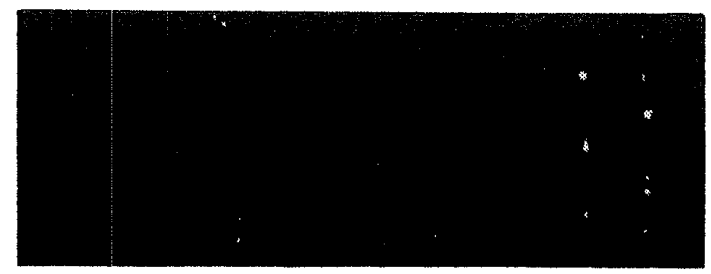

(16-7), $140 \mu$

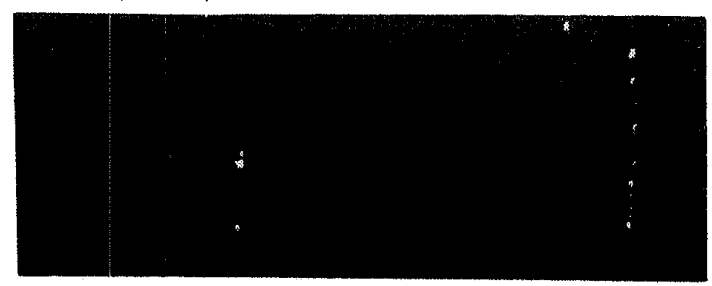

(16-9), $183 \mu$

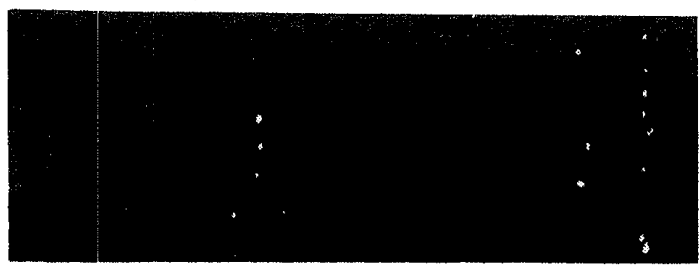

$a=15.5 \mathrm{~kg} / \mathrm{mm}^{2}, N_{1}=1.3 \times 10^{6}$

Fig. 11 Diffraction patterns of specimen No. 16 
the thickness of the damaged layer can be determined by the sharpness of the deffraction spots.

Fig. 12 are the patterns (no filter was used, dia. of beam was $1.08 \mathrm{~mm}$ ) of plain specimen (43) (c. f. Fig. 2) which failed under the stress $14.0 \mathrm{~kg}$ / $\mathrm{mm}^{2}$. Since the fatigue limit of the material was about $13 \mathrm{~kg} / \mathrm{mm}^{2}$ as shown in Fig. 2 and the dia. of the specimen was about $11 \mathrm{~mm}$, the part of the specimen which was subjected to the stress above its fatigue limit reached about $400 \mu$ below the surface. In Fig. 12 the blurring of the spots decreases as the diffracting part deepens. The spots from the layer about $450 \mu$ beneath the surface are

$(43-1)$, Surface sharp, showing that the deformation of crystal planes nearly stopped there. The diffraction spots of the specimen (32) (c. f. Fig. 13) tested under the stress of $14.5 \mathrm{~kg} / \mathrm{mm}^{2}$ show also the same result. In the latter case, however, the layer about $580 \mu$ beneath the surface was subjected to a stress above its fatigue limit $\left(13 \mathrm{~kg} / \mathrm{mm}^{2}\right)$. We see, from Fig. 13, that the diffraction patterns from the layer about $600 \mu$ beneath the surface is sharp and so the deformation of crystal planes ceased near this part.

Those results suggest that the expansion of the diffraction spots takes place only in the layer

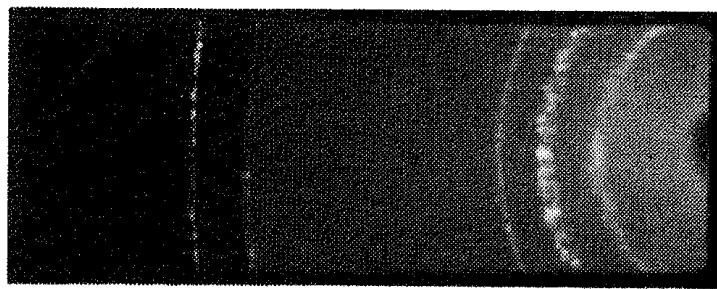

(43-2), $200 \mu$

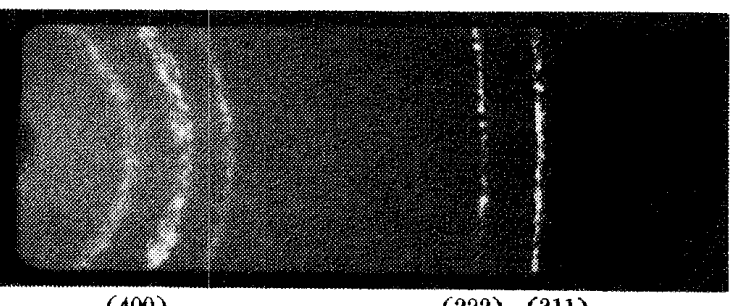

(222) (311)

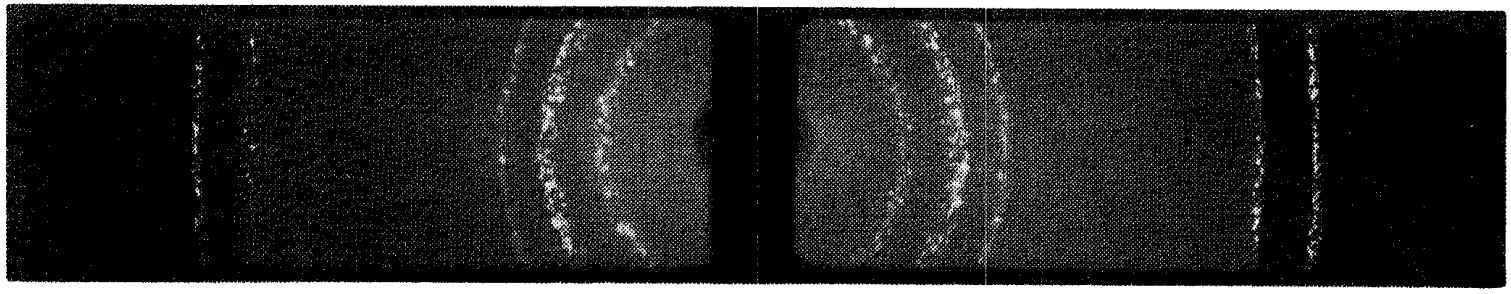

$(43-4), 300 \mu$

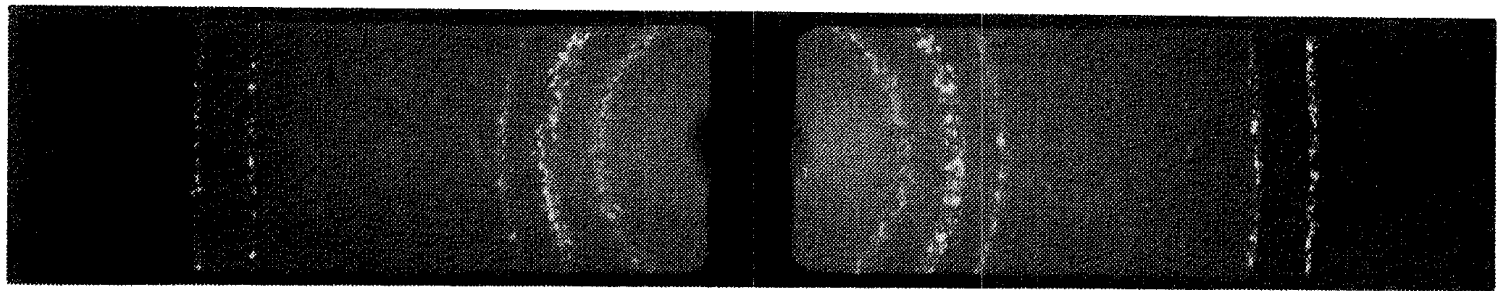

$(43-6), 400 \mu$

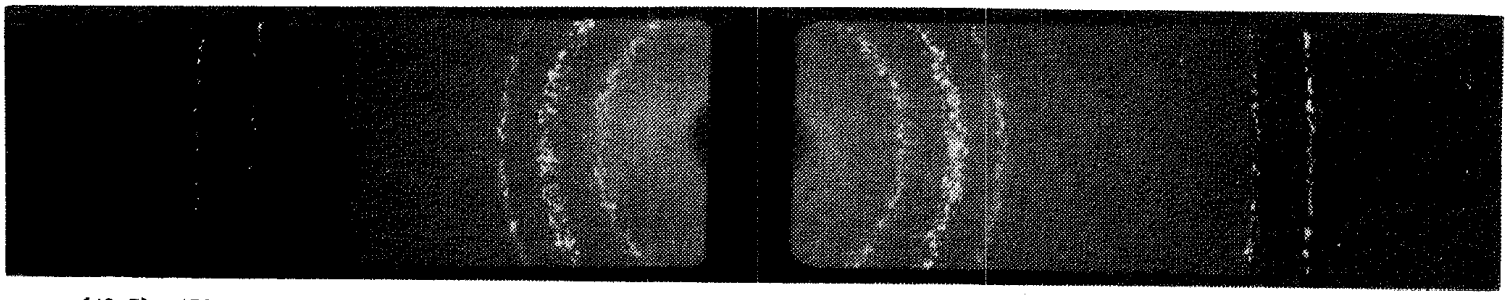

$(43-7), 450 \mu$

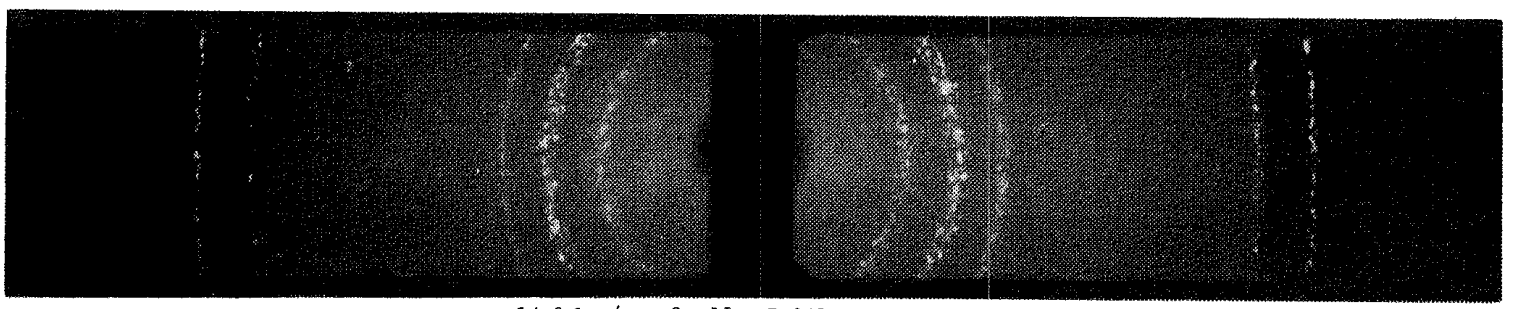

$\sigma=14.0 \mathrm{~kg} / \mathrm{mm}^{2}, N_{1}=5.6439 \times 10^{6}$, broken

Fig. 12 Diffraction patterns of spcimen No. 43 
subjected to the stress above its fatigue limit.

The results of A.P. procedure and of $X$-ray investigation tell us that the damage of the part below $C D$ in Fig. 9 must be very small compared with the damage in $A B C D$. In spete of this the specimens fail when the magnitude of the fibre stress is larger than its fatigue limit. To reconcile those discrepancies it is natural to think that when the thickness of the damaged layer reaches a certain value, microcracks will develop there and propagate into the specimen and causing eventual failure of the specimen as the stress repetition is continued.

(32-1), Surface

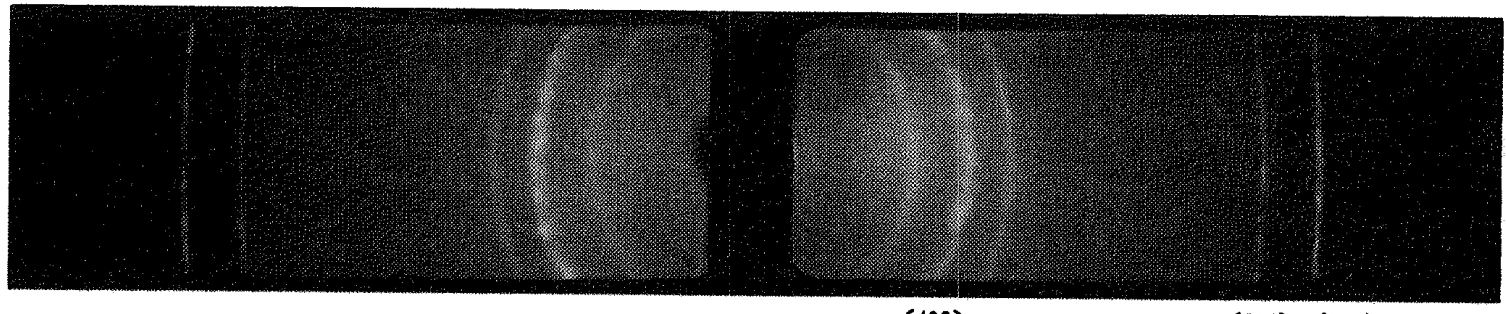

$(32-2), 200 \mu$

$(400)$

(222) (311)

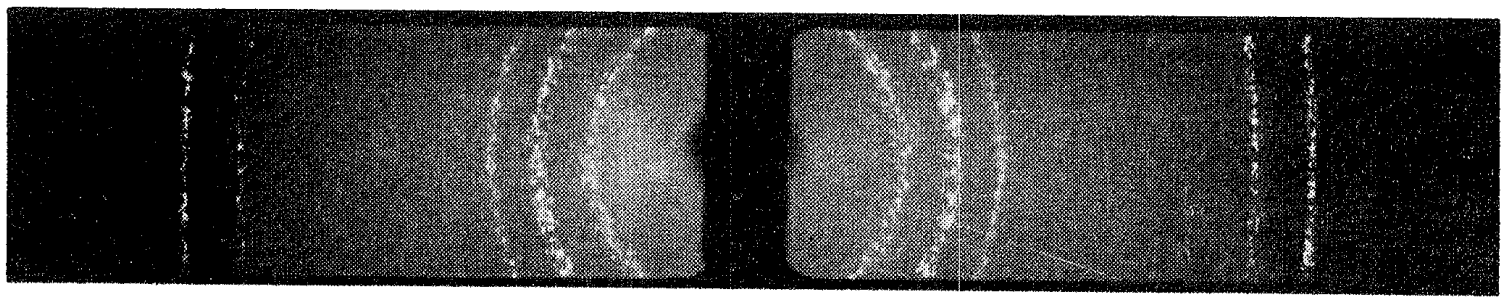

$(32-3), 230 \mu$

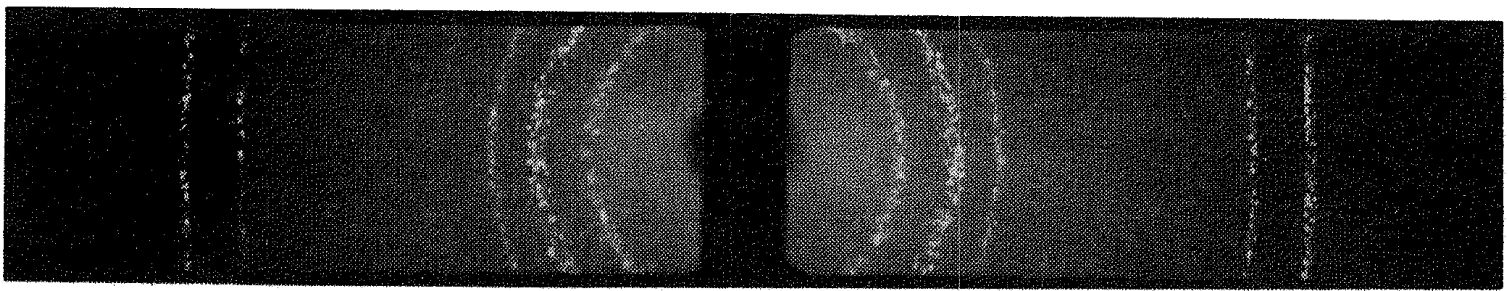

$(32-5), 535 \mu$

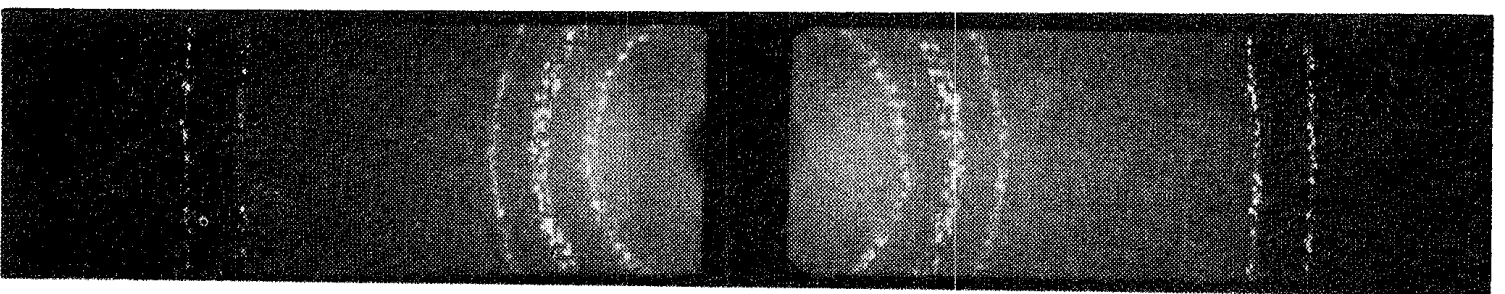

$(32-6), 600 \mu$

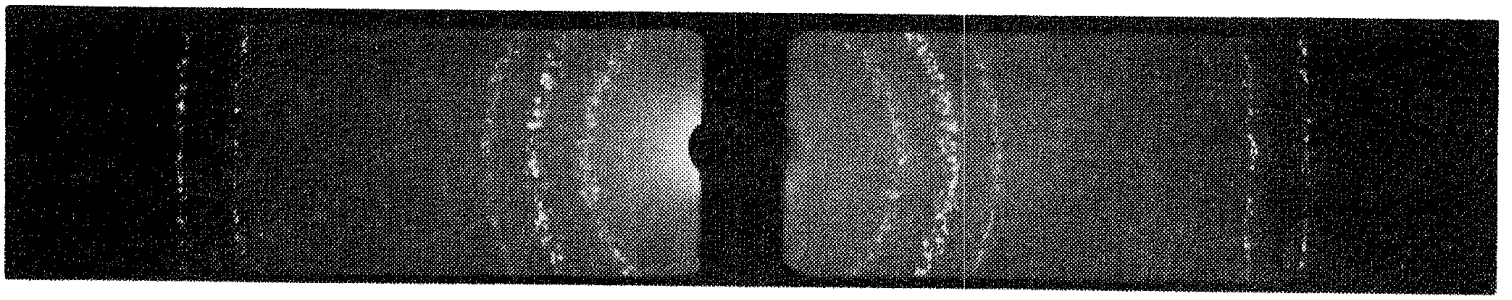

$\sigma=14.5 \mathrm{~kg} / \mathrm{mm}^{2}, N_{1}=6.5947 \times 10^{6}$, broken

Fig. 13 Diffraction patterns of specimen No. 32 
initial crack will develop in the inner grains such as $\mathrm{A}^{\prime} \mathrm{B}^{\prime} \mathrm{B}^{\prime \prime} \mathrm{A}^{\prime \prime}$ or $\mathrm{A}^{\prime \prime} \mathrm{B}^{\prime \prime} \mathrm{DC}$ etc.

In both cases the first fatigue crack will develop in the surface or near the surface of the specimen. In our experiments we can not ascertain the location of the grain in which the first microcrack developed.

Watanabe ${ }^{(5)}$ and Wadsworth ${ }^{(6)}$ reported that they found fatigue crack in the surface of the specimen stressed to their fatigue limit and they concluded that fatigue limit was a stress under which fatigue crack did not propagate at all.

We infer that the initial crack will develop in the layer stressed above a stress $\sigma_{w_{0}}$ (Fig. 9) which is nearly equal to the fatigue limit of a plain specimen. Even in the plain specimen, exactly speaking, fatigue limit is expressed by the fibre stress $A B$ in Fig. 9 (b) and so it does not equal to $\sigma_{w_{0}}$ exactly.

The condition that fatigue crack will start on or near the surface of the specimen seems to have intimate relations with the thickness of the damaged layer. On the other hand we know that fatigue limit of notched specimen can be obtained by considering a thin surface layer at the root of the notch. This and above fact suggest that in order that a crack may develop in damaged layer a certain thickness of the damaged layer is necessary.

\section{Conclusion}

About fatigue damage of 7-3 brass specimens under rotary bending stress with repeated annealing and polishing procedure, as well as by taking X-ray diffraction patterns, the author reached the following conclusions.

a) Fatigue damage due to stress above fatigue limit concentrates near the surface of the specimen.
The damage can not be removed by stress relief annealing.

b) Fatigue damage preceeds grain by grain from the surface into the interior of the specimen. The thickness of the damaged layer is a function of the magnitude of applied stress and its number of repetitions.

c) Most part of the fatigue damage in the interior part of the specimen is of strain hardening character and can be removed by stress relief annealing though not perfectly.

d) By taking $\mathrm{X}$-ray deffraction patterns of fatigued specimens it is conculded that when the thickness of the damaged layer reaches a certain value, microcracks will develop there and their propagation causes an eventual fracture of the specimen.

\section{Acknowledgments}

The author wishes to thank Ass. Prof. T. Matake for carrying the fatigue tests and Assistant H. Oho for his aids in electro-polishing of the specimens. He gratefully acknowledges the offer of the material used in this experiment, by Dr. K. Takeuchi of the Sumitomo Light Alloy Manufacturing Co., Japan.

\section{References}

(1) T. Isibasi : Bulletin of JSME, Vol. 6, No. 23 (1963), p. 430.

(2) K. Setoguchi: Preprint of the 40th Annual Meeting of Japan Soc. Mech. Engrs., No. 85 (1963), p. 5.

(3) N.J. Petch: J. Iron Steel Inst., Vol. 174 (1953), p. 25 .

(4) H. Okubo et al.: Trans. Japan Soc. Mech. Engrs. Vol. 28, No. 191 (1962), p. 774.

(5) J. Watanabe and Y. Kumada: Preprint of the $38 \mathrm{th}$ Annual Meeting of Japan Soc. Mech. Engrs., No.37 (1961), p. 67

(6) N.J. Wadsworth: Phil. Mag., Vo1. 6, 8-ser.(1961), p. 397 . 